\title{
PREVALENSI TERMINAL ILLNESS DI RSUD JENDERAL AHMAD YANI METRO
}

\section{TERMINAL PREVALENCE OF ILLNESS IN RSUD JENDERAL AHMAD YANI METRO}

\author{
Supardi ${ }^{1}$, Ludiana ${ }^{2}$ \\ 1,2 Akper Dharma Wacana Metro, \\ e-mail; supardibmw@gmail.com
}

\begin{abstract}
ABSTRAK
Kondisi terminal adalah suatu kondisi dimana seseorang mengalami sakit atau penyakit yang tidak mempunyai harapan untuk sembuh dan menuju pada proses kematian dalam 6 bulan atau kurang. Data prevalensi terminal illness pada saat ini tidak tersedia secara pasti tetapi dapat dilihat dari data yang tersebar dalam berbagai penyakit yang merupakan bagian dari jenis jenis penyakit yang masuk dalam kondisi terminal illness antara lain, kanker, dibetes millitus, paru obstruksi kronis, cystic fibrosis, stroke, Parkinson, gagal jantung, genetika dan HIV/AIDS. Metode Penelitian : adalah penelitian deskriptif analitik dengan jumlah populasi sebanyak 2051, sedangkan untuk sampel digunakan dengan total sampel. Data yang digunakan adalah data sekunder dari Rumah sakit Ahmad Yani Metro yang ditabulasikan selanjutnya di intrepretasikan. Hasil : Prevalensi terminal illness dapat digambarkan sebagai berikut kanker 447 (21,89\%), Diabetes mellitus 241 (11,75\%), Paru Obstruksi Kronis 169 (8,24\%), penyakit stroke $662(32,28 \%)$, Parkinson 6 (0,29\%), gagal jantung 496 (24,18\%), HIV/AIDS 28 (1,37\%). Kesimpulan : Penelitian ini memberikan gambaran bahwa kelompok umur $\geq 60$ tahun paling banyak masuk dalam terminal illness, sedangkan khusus untuk penyakit HIV /AIDS yaitu kelompok umur $<40$ tahun yang paling banyak masuk dalam terminal illnes.
\end{abstract}

Keywords: Terminal illness, Kematian, Kesabaran

\begin{abstract}
Introduction: A terminal condition is a condition in which a person experiences an illness or illness that has no hope of recovery and leads to the process death in 6 months or less. Data on the prevalence of terminal illness at this time is not available with certainty but can be seen from the data scattered in various diseases that are part of the types of diseases that enter the terminal illness conditions, among others, cancer, millitus drops, chronic obstructive pulmonary, cystic fibrosis, stroke , Parkinson's, heart failure, genetics and HIV / AIDS. Method: is a descriptive analytic study with a population of 2051, while the sample is used with a total sample. The data used are secondary data from Ahmad Yani Metro Hospital, which is tabulated further interpreted. Results: Terminal illness prevalence can be described as follows cancer 447 (21.89\%). Diabetes mellitus 241 (11.75\%), Chronic Obstruction Lung 169 (8.24\%), stroke 662 (32.28\%), Parkinson 6 (0.29\%), heart failure 496 (24.18\%), HIV / AIDS 28 (1.37\%). Conclusion: This study illustrates that the age group of 260 years is the most included in terminal illness, whereas specifically for HIV / AIDS, the age group $<40$ years is the most included in terminal illnes.
\end{abstract}

\section{Keywords: Terminal illness, Death. Patience}




\section{PENDAHULUAN}

Meningkatnya jumlah klien dengan penyakit yang belum dapat disembuhkan baik pada dewasa dan anak seperti penyakit kanker, penyakit degeneratif, penyakit paru obstruktif kronis, cystic fibrosis, stroke, Parkinson, gagal jantung/heart failure, penyakit genetika dan penyakit infeksi seperti HIV/AIDS memerlukan perawatan dan pelayanan kesehatan paliatif. Ketika seorang klien divonis menderita suatu penyakit yang tidak bisa disembuhkan, seketika itu pula kematian sudah berada di pelupuk mata. Kondisi terminal adalah suatu kondisi dimana seseorang mengalami sakit atau penyakit yang tidak mempunyai harapan untuk sembuh dan menuju pada proses kematian dalam 6 bulan atau kurang ${ }^{1}$.

Data Prevalensi terminal illness pada saat ini dapat dilihat dari yang tersebar dalam berbagai penyakit yang merupakan bagian dari jenis jenis penyakit yang masuk dalam kondisi terminal illness. Menurut keputusan menteri kesehatan RI No : 812/Menkes/SK/VII/2007 tentang kebijakan perawatan paliatif bahwa penyakit yang termasuk dalam kondisi ini antara lain : 1) penyakit kanker, 2) penyakit degenerative, 3) penyakit paru obstruksi kronis, 4) cystic fibrosis, 5) stroke, 6) Parkinson, 7) gagal jantung/heart failure, 8) penyakit genetika dan 9) penyakit infeksi seperti HIV. Dari info datin pusat data dan informasi kementrian kesehatan Republik Indonesia bahwa Penyakit kanker merupakan salah satu penyebab kematian utama di seluruh dunia. Pada tahun 2012, sekitar 8,2 juta kematian disebabkan oleh kanker. Kanker paru, hati, perut, kolorektal, dan kanker payudara adalah penyebab terbesar kematian akibat kanker setiap tahunnya ${ }^{2}$. Survei dari World Health Organization (WHO), diketahui 8,4 juta kasus DM di Indonesia angka ini akan terus naik sampai dengan tahun 2030 menjadi 21,3 juta penderita. DM menjadi penyebab sekitar $60 \%$ kematian dan $43 \%$ penyebab kematian di dunia ${ }^{3}$.

\section{METODE}

Penelitian ini menggunakan desain deskriptif, dimana penelitian dilakukan pada satu periode waktu tertentu, selanjutnya sampel diukur satu kali dan tidak dilakukan Follow-up atau kelanjutannya (Eko Budiarto, 2002). Rancangan penelitiannya cross-sectional yakni untuk melihat gambaran angka kejadian terminal illness di RSUD Jenderal Ahmad Yani Kota Metro selama tahun 2018 dari bulan januari sampai dengan bulan Desember.

Data penelitian di analisis untuk melihat distribusi frekuensi subjek penelitian yang didasarkan pada Usia, Jenis kelamin dan penyakit terminal yang terdistribusi dalam penyakit Kanker, Diabetes militus, PPOK, cystic fibrosis, Stroke, Parkinson, gagal Jantung, genetic dan HIV/AIDS

\section{HASIL}

Penelitian ini dikerjalan dalam kurun waktu yang cukup singkat yaitu sekitar satu bulan, dengan total sampel yang ada yakni berjumlah 2051 orang yang di diagnose mengalami terminal 
illness, dari jumlah tersebut dilakukan analisis dan terdistribusi dalam tujuh penyakit. Penyakit Kanker, PPOK, Strouk, Parkinson, Diabetes Militus, HIV, Penyakit jantung, sedangkan penyakit cystic fibrosis dan penyakit genetika tidak ditemukan selama tahun 2018.

Karakteristik responden dalam penelitian ini dari sisi variable epidemiologi dapat digambarkan secara jelas dapat digambarkan sebagai berikut :

Tabel. 1

Distribusi responden terminal illness berdasarkan jenis kelamin dan kelompok umur

\begin{tabular}{lrr} 
Karakteristik & Jumlah & $\%$ \\
\hline Jenis Kelamin & & \\
Laki-laki & 1024 & 49,9 \\
Perempuan & 1027 & 50,1 \\
Kelompok umur & & \\
1: $<40$ tahun & 167 & 8,14 \\
2: $40-49$ tahun & 280 & 13,65 \\
3: $50-59$ tahun & 527 & 25,70 \\
4: $\geq 60$ tahun & 1077 & 52,51
\end{tabular}

Dari tabel 1. Yang telah disajikan tersebut diatas dapat kita lihat bahwa responden berdasarkan karakteristik jenis kelamin dapat digambarkan sebagai berikut; jenis kelamin laki-laki sebanyak $1024(49,9 \%)$ dan untuk perempuan sebanyak 1027 (50,1\%), selanjutnya berdasarkan karakteristik umur dapat diketahui untuk kelompok umur kurang dari 40 tahun sebanyak 167 (8,14\%), kelompok umur 40-49 tahun sebanyak 280 (13,65\%), dan kelompok umur 5059 tahun sebanyak $527(25,70 \%)$, serta kelompok umur $\geq 60$ tahun keatas sebanyak 1077 $(52,51 \%)$
Tabel. 2

Distribusi kondisi pasien saat meninggalkan Rumah Sakit

$\begin{array}{lcc}\text { Kondisi pasien } & \text { Jumlah } & \% \\ \text { APS } & 28 & 1,36 \\ \text { Rujuk } & 22 & 1,07 \\ \text { Meninggal } & 284 & 13,84 \\ \text { Perbaikan } & 1.558 & 75,96 \\ \text { Membaik } & 159 & 7,76 \\ ------------ \\ \text { Jumlah } & 2.051 & 100,00\end{array}$

Dari tabel 2 yang menyajikan distribusi kondisi pasien saat meninggalkan rumah sakit dapat diketahui sebagai berikut ; kondisi pasien yang meminta pulang paksa (APS) sebanyak 28 orang $(1,36 \%)$, pasien yang di rujuk diketahui sebanyak 22 orang (1,07\%), pasien yang meninggal dunia diketahui sebanyak 284 orang $(13,84 \%)$, dan pasien dengan kondisi perbaikan diketahui sebanyak 1.558 orang $(75,96 \%)$, serta pasien dengaan kondisi membaik diketahui sebanyak 159 orang $(7,76 \%)$

Tabel 3.

Distribusi responden berdasarkan sebaran penyakitnya

\begin{tabular}{|c|c|c|}
\hline Sebaran penyakit & Jumlah & $\%$ \\
\hline Penyakit kanker & : 449 & 21.89 \\
\hline Penyakit (DM) : 241 & 11.75 & \\
\hline Penyakit PPOK : 169 & 8.24 & \\
\hline $\begin{array}{l}\text { Penyakit cystic fibrosis: } \\
\text { penyakit stroke : } 662\end{array}$ & $\begin{array}{r}0 \\
32.28\end{array}$ & 0 \\
\hline Penyakit Parkinson & $: \quad 6$ & 0.29 \\
\hline Penyakit gagal jantung: & : 496 & 24.18 \\
\hline Penyakit genetika & $: \quad 0$ & 0 \\
\hline Penyakit HIV/AIDS & 28 & 1.37 \\
\hline umlah & : 2.051 & 100.00 \\
\hline
\end{tabular}


Dari tabel 3 yang menyajikan data sebaran penyakit dapat diketahui sebagai berikut; penyakit kanker diketahui sebanyak 447 orang (21,89\%), penyakit Diabetes mellitus diketahui 241 (11,75\%), penyakit Paru Obstruksi Kronis diketahui 169 (8,24\%), penyakit cystic Fibrosis tidak ditemukan $(0 \%)$, penyakit stroke diketahui sebanyak 662 (32,28\%), penyakit Parkinson diketahui sebanyak 6 orang $(0,29 \%)$, penyakit gagal jantung diketahui sebanyak 496 (24,18\%), penyakit genetika tidak diketemukan yakni $(0 \%)$, dan penyakit HIV diketahui sebanyak 28 orang $(1,37 \%)$

Tabel 4

Distribusi terminal illness berdasarkan diagnosa penyakit dan kelompok umur

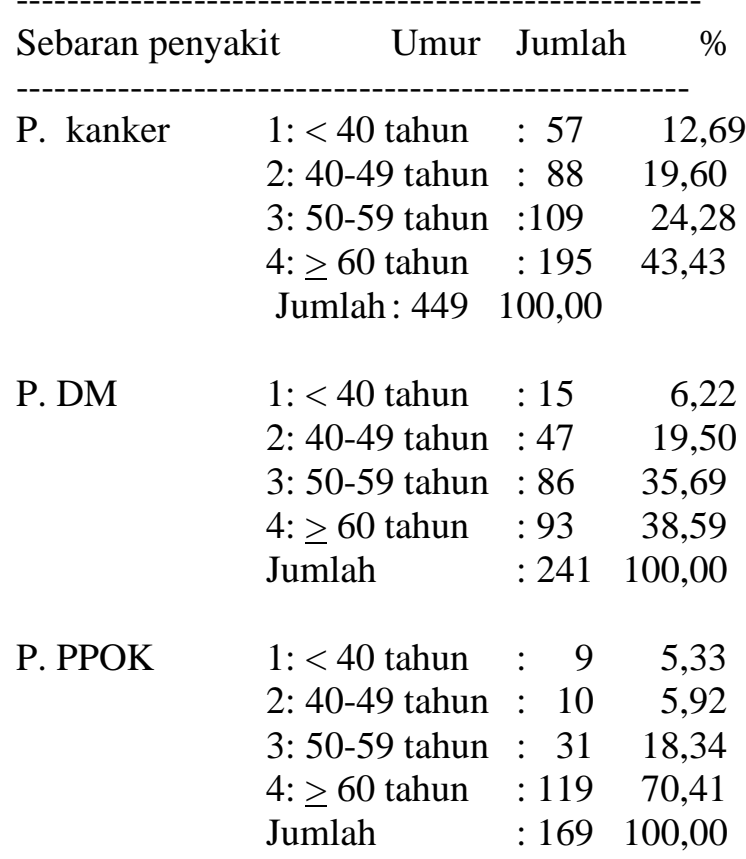

P. cystic fibrosis 1: $<40$ tahun : 0

$\begin{array}{ll}\text { 2: } 40-49 \text { tahun } & : 0 \\ \text { 3: 50-59 tahun } & : 0 \\ \text { 4: } \geq 60 \text { tahun } & : 0 \\ \text { Jumlah } & : 0\end{array}$

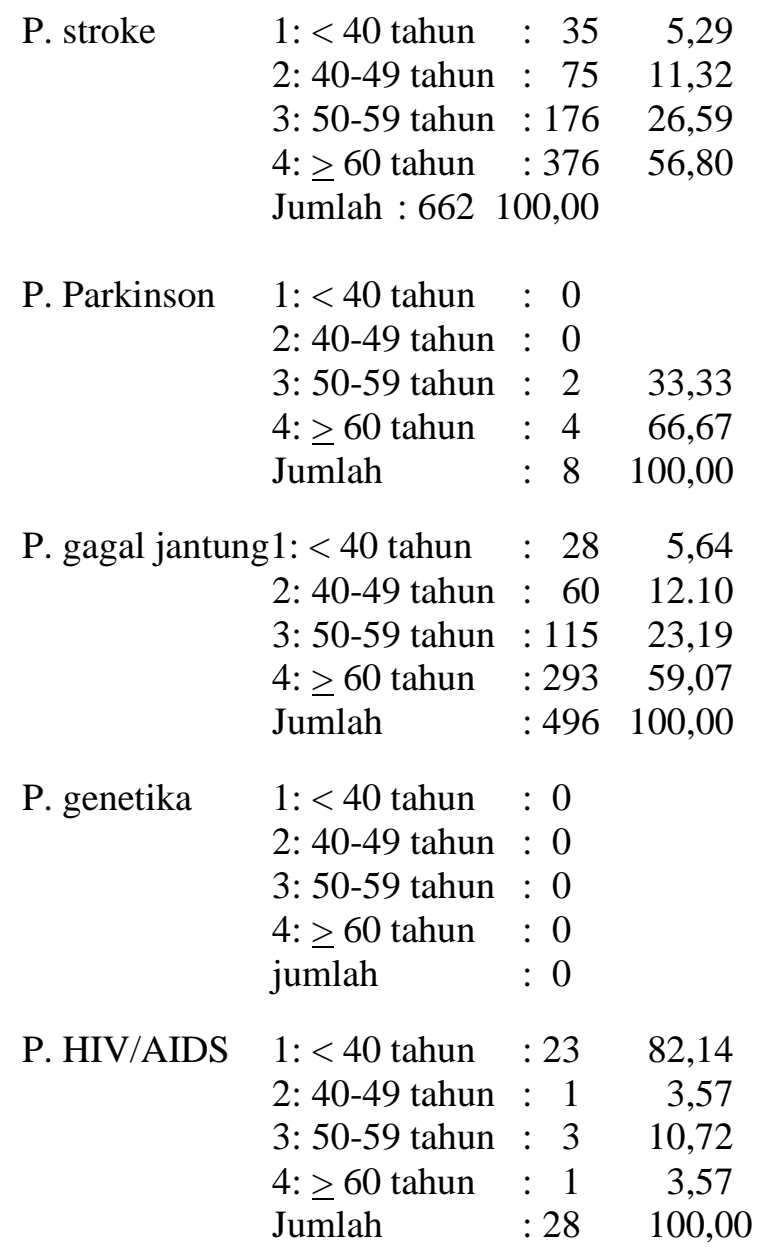

Dari tabel 4. Dapat diketahui distribusi terminal illness berdasarkan diagnose penyakit dan kelompok umur adalah sebagai berikut : Penyakit kanker dengan kelompok umur $<40$ tahun diketahui sebanyak 57 orang (12,69\%), kelompok umur 40-49 tahun diketahui sebanyak 88 orang $(19,60 \%)$, kelompok umur 50-59 ntahun diketahui sebanyak 109 orang (24,28\%), kelompok umur $\geq 60$ tahun diketahui sebanyak 195 orang $(43,43 \%)$. Penyakit Diabetes Millitus dengan kelompok umur $<40$ tahun 15 orang $(6,22 \%)$, kelompok umur 40-49 tahun diketahui sebanyak 47 orang $(19,50 \%)$, kelompok umur 5059 tahun diketahui sebanyak 86 orang $(35,69 \%)$, kelompok umur $\geq 60$ tahun diketahui sebanyak 
93 orang (38,59\%). Penyakit POK dengan kelompok umur $<40$ tahun diketahui sebanyak 9 orang (5,33\%), kelompok umur 40-49 tahun diketahui sebanyak 10 orang $(5,92 \%)$, kelompok umur 50-59 tahun diketahui 31 orang (18,34\%), kelompok umur $\geq 60$ tahun diketahui sebanyak 119 orang (70,41\%). Penyakit cystic fibrosis dengan kelompok umur $<40$ tahun diketahui sebanyak 0 orang (0\%), kelompok umur 40-49 tahun diketahui sebanyak 0 orang (0\%), kelompok umur 50-59 tahun diketahui 0 orang (0\%), kelompok umur $\geq 60$ tahun diketahui sebanyak 0 orang $(0 \%)$. Penyakit stroke dengan kelompok umur $<40$ tahun diketahui sebanyak 35 orang $(5,29 \%)$, kelompok umur 40-49 tahun diketahui sebanyak 75 orang $(11,32 \%)$, kelompok umur 50-59 tahun diketahui 176 orang $(26,59 \%)$, kelompok umur $\geq 60$ tahun diketahui sebanyak 376 orang $(56,80 \%)$. Penyakit Parkinson dengan kelompok umur $<40$ tahun diketahui sebanyak 0 orang $(0 \%)$, kelompok umur 40-49 tahun diketahui sebanyak 0 orang (0\%), kelompok umur 50-59 tahun diketahui 2 orang (33,33\%), kelompok umur $\geq 60$ tahun diketahui sebanyak 4 orang $(66,67 \%)$. Penyakit gagal jantung dengan kelompok umur $<40$ tahun diketahui sebanyak 28 orang (5,64\%), kelompok umur 40-49 tahun diketahui sebanyak 60 orang (12.10\%), kelompok umur 50-59 tahun diketahui 115 orang $(23,19 \%)$, kelompok umur $\geq 60$ tahun diketahui sebanyak 293 orang $(59,07 \%)$. Penyakit genetic dengan kelompok umur $<40$ tahun diketahui sebanyak 0 orang $(0 \%)$, kelompok umur 40-49 tahun diketahui sebanyak
0 orang (0\%), kelompok umur 50-59 tahun diketahui 0 orang $(0 \%)$, kelompok umur $\geq 60$ tahun diketahui sebanyak 0 orang $(0 \%)$. Penyakit HIV/AID dengan kelompok umur $<40$ tahun diketahui sebanyak 23 orang $(82,14 \%)$, kelompok umur 40-49 tahun diketahui sebanyak 1 orang $(3,57 \%)$, kelompok umur 50-59 tahun diketahui 3 orang $(10,72 \%)$, kelompok umur $\geq$ 60 tahun diketahui sebanyak 1 orang $(3,57 \%)$

\section{PEMBAHASAN}

Dari penelitian ini dapat di peroleh gambaran bahwa penyakit yang termasuk dalam terminal illness di Rumah Sakit Umum Daerah Jenderal Ahmad Yani Kota Metro sebanyak 2051 penderita selama tahun 2018. Pasien terminal illness ini terdistribusi dalam 7 (tujuh) penyakit dari 9 (Sembilan) penyakit yang termasuk dalam keputusan menteri kesehatan Republik Indonesia Nomor : 812/Menkes/SK/VII/2007 tentang kebijakan perawatan paliatif yaitu Penyakit Kanker, Diabetes Millitus, Paru Obstruksi Kronis, Stroke, Parkinson, Gagal Jantung, HIV/AIDS, sedangkan 2 (dua) penyakit yakni Penyakit genetika dan Cystic Fibrosis tidak ditemukan pasien yang berobat ke RSUD Ahmad Yani Metro selama tahun 2018. Hasil penelitian menunjukan bahwa bahwa jenis kelamin antara laki-laki dan perempuan yaitu 1024 laki-laki, dan 1027 perempuan yang dalam hal terdapat perbedaan tiga orang.

Hasil penelitian di Rumah Sakit Umum Daerah Kota Metro selama tahun 2018 menunjukan bahwa kelompok umur $\geq 60$ tahun sebanyak 
1077 kasus (52,51\%) penderita, diikuti kelompok umur 50-59 tahun sebanyak 527 (25,70\%), kelompok umur 40-49 tahun sebanyak 280 $(13,65 \%)$ dan kelompok umur $<40$ tahun sebanyak $167 \quad(8,14 \%)$ seiring dengan bertambahnya umur seseorang maka sangat berisiko terkena penyakit dengan stadium terminal hal ini disebabkan semakin bertambahnya umur maka penurunan fungsi tubuh secara perlahan namun pasti turut menyertainya.

Angka kejadian terminal illness di Rumah Sakit Umum Jenderal Ahmad Yani Metro selama tahun 2018 diketahui sebanyak 2051 penderita. Angka kejadian tersebut terdistribusi dalam 7 (tujuh) penyakit adalah sebagai berikut: penyakit kanker dengan angka kejadian 447 kasus (21,89\%) selama tahun 2018. Penyakit kanker dengan 447 kasus tersebut memiliki umur $<40$ tahun sebanyak 57 orang (12,69\%), 40-49 tahun sebanyak 88 orang (19,60\%), 50-59 tahun 109 orang $(24,28 \%)$ dan $\geq 60$ tahun 195 orang $(43,43 \%)$. Hal ini sejalan dengan penelitian yang dilakukan oleh Soelastri (2011) yang menyatakan bahwa kelompok umur yang lebih tua (> 41 tahun ) rentan terhadap penyakit kanker yakni sebesar $41.7 \%{ }^{4}$. Penyakit Diabetes Millitus diketahui sebanyak 241 kasus, umur < 40 tahun diketahui sebanyak 15 orang $(6,22 \%)$, umur 40-49 tahun diketahui sebanyak 47 orang $(19,50 \%)$, umur 5059 di ketahui sebanyak 86 orang $(35,59 \%)$ dan umur $\geq 60$ tahun diketahui 195 orang $(43,43 \%)$. Hasil ini memberikan gambaran bahwa semakin berusia lanjut semakin beresiko untuk terkena penyakit Diabetes Millitus, hal ini sejalan dengan hasil penelitian yang dilakukan oleh Rita khairani (2007) bawah usia 60-70 tahun memiki angka kejadian yang sangat tinggi terhadap penyakit diabetes mellitus yaitu sebesar $84,2 \%{ }^{5}$. Prevalensi Terminal Illnes yang berasal dari Penyakit Paru Obstruksi Kronis (PPOK) diketahui sebanyak 169 orang, dengan umur $<40$ tahun sebanyak 9 orang $(5,33 \%)$, umur $40-49$ tahun sebanyak 10 orang $(5,92 \%)$, umur 50-59 sebanyak 31 orang $(18,34 \%)$ dan umur $\geq 60$ tahun 119 orang $(70,41 \%)$ hasil ini memberikan gambaran bahwa penderita PPOK terbanyak adalah pada usia lanjut. Hasil ini sesuai dengan penelitian yang dilakukan oleh Nia Permatasari (2016) prevalensi PPOK pada usia > 65 tahun mencapai $53,3 \%{ }^{6}$. Prevalensi terminal illness yang berasal dari diagnosa penyakit stroke diketahui sebanyak 662 orang, dengan umur $<40$ tahun sebanyak 35 orang $(5,29 \%)$, umur 40-49 tahun sebanyak 75 orang (11,32\%), umur 50-59 tahun sebanyak 176 orang $(26,59 \%)$ dan umur $\geq$ 60 tahun sebanyak 376 orang $(56,80 \%)$ hasil ini menggambarkan bahwa penyakit stroke yang terbanyak adalah di usia lanjut. Hasil ini sama dengan hasil penetian Aisyah Muhrini Sofyan (2013) bahwa prevalensi penyakit stroke dengan umur > 55 tahun sebesar $67,5 \%{ }^{7}$. prevalensi terminal illness yang berasal dari penyakit Parkinson diketahui sebanyak 6 orang, dengan umur 50-59 tahun sebanyak 2 orang $(33,33 \%)$ dan umur $\geq 60$ tahun sebanyak 4 orang $(66,67 \%)$. Hasil ini memberikan gambaran bahwa penderita penyakit Parkinson adalah mereka yang berumur 
lanjut memiliki resiko yang sangat besar. Hasil penelitian ini sama dengan yang dilakulkan oleh astir Andra Sari Lestari (2015) bahwa usia 60-70 tahun memiliki proporsi yang lebih banyak mengidap Parkinson ${ }^{8}$. Prevalensi terminal illness yang berasal dari penyakit gagal jantung diketahui sebanyak 496 orang, dengan umur $<40$ tahun 28 orang $(5,64 \%)$, umur $40-49$ tahun diketahui sebanyak 60 orang $(12,10 \%)$, umur 5059 tahun diketahui sebanyak 115 orang $(23,19 \%)$ dan umur $\geq 60$ tahun diketahui sebnayak 293 orang $(59,07 \%)$. Hasil ini memberikan gambaran bahwa penderita penyakit jantung adalah mereka yang berumur 60 tahun keatas sangat beresiko. Hasil penelitian ini di dukung oleh penelitian yang dilakukan oleh Yayang Harigustian (2016) bahwa kelompok usia 61-65 tahun diketahui mengalami gagal jantung terbanyak dengan angka mencapai 59,38\% $\%$. Prevalensi terminal Illness yang berasal dari Penyakit HIV/AIDS diketahui sebanyak 28 orang, dengan umur $<40$ tahun sebanyak 23 orang (82,14\%), umur 40-49 tahun sebanyak 1 orang $(3,57 \%)$, umur 50-59 sebanyak 3 orang $(10,72 \%)$ dan umur $\geq 60$ tahun sebanyak 1 orang $(3,57 \%)$. Hasil penelitian ini memberikan gambaran bahwa penyakit HIV/AIDS diketahui banyak pada umur $<40$ tahun. Hasil penelitian ini di dukung dengan penelitian yang dilakukan oleh Phey Liana 2018 bahwa kelompok umur muda < 40 tahun diketahui mengidap HIV/AIDS sebanyak $83,7 \%{ }^{10}$.

Hasil penelitian terminal illness ini juga memberikan gambaran kondisi pasien saat meninggalkan rumah sakit bahwa terdapat angka kejadian pasien pulang paksa sebanyak 28 orang $(1,36 \%)$, pulang dengan rujukan 22 orang $(1,07 \%)$, Pulang meninggal dunia 284 orang $(13,85 \%)$, pulang dengan perbaikan sebanyak 1.558 orang $(75,96 \%)$ dan pulang dengan konsisi baik sebanyak 159 orang (7,76\%). Sesuai dengan Keputusan Menteri Kesehatan Republik Indonesia Nomor : 812/Menkes/Sk/Vii/2007, perihal Kebijakan Perawatan Paliatif, maka pasien yang berada di Rumah Sakit Jenderal Ahmad Yani Metro perlu mendapatkan perawatan palliative.

\section{KESIMPULAN}

Penelitian ini telah berhasil memberikan gambaran umur jenis, kelamin, jenis penyakit, dan jumlah pasien yang ada di Rumah Sakit Jenderal Ahmad Yani Metro yang termasuk dalam Penyakit terminal illness. Prevalensi terminal illness di Rumah Sakit Umum Daerah Jenderal Ahmad Yani Metro selama tahun 2018 sebesar 2051 orang, selanjutnya terdistribusi kedalam Penyakit kanker 449 orang, Diabetes Millitus 241 orang, PPOK 169 orang, Stroke 662 orang, Parkinson 6 orang, gagal jantung 496 dan HIV/AIDS 28 orang, sedangkan Penyakit Genetika dan cystic fibrosis tidak ditemukan kasusnya. Penelitian ini juga memberikan gambaran bahwa kelompok umur $\geq 60$ tahun paling banyak masuk dalam terminal illness kecuali satu penyakit HIV /AIDS yaitu kelompok umur $<40$ tahun. 


\section{DAFTAR PUSTAKA}

1. Depkes RI Pusdiknakes. (1995). Asuhan Keperawatan Pasien dengan Gangguan dan Penyakit kronik dan terminal " Depkes RI. Jakarta

2. Kementerian Kesehatan RI. (2015). Stop Kanker Info Datin. Jakarta: Pusat Data dan Informasi Kementerian Kesehatan RI

3. Wild S, Sicree R, Roglic G, King H, Green A. Global Prevalence of diabetes:estimates for the year 200 and projections for 2030. Diabetes care 2004;27: 1047-53.

4. Soelastri, dkk. Hubungan Dukungan Keluarga Terhadap Kecemasan pada Pasien Kanker yang Menjalani Kemoterapi di RSUD Arifin Achmad Provinsi Riau.

5. Khairani Rita (2007). Prevalensi Diabetes Militus dan Hubungannya dengan Kualitas Hidup Usia di Masyarakat. (http//www.Univmed.org/ejurnal/index.php/ Medicine.article/View/292)

6. Permatasari Nia, dkk (2016). Gambaran Status Gizi pada Pasien Penyakit Paru Obstruktif Kronis (PPOK) yang Menjalani Rawat Jalan di RSUD Arifin Achmad Pekanbaru.

(http//JOM.Unri.ac.id/index.php/jomFDOK/ srticle/view/10431/10089)

7. Sofyan Aisyah Muhrini, dkk (2013). Hubungan Umur, Jenis Kelamin, dan
Hipertensi dengan Kejadian Stroke. OJS.UHO.ac.id/index.php/Medula/article/Vi ew/182.Medula Vol 1. No 1 (2013)

8. Lestari Astri Andra Sari Yunita, dkk (2015). Hubungan Penggunaan Obat Antihipertensi dengan Angka Kejadian Penyakit Parkinson di RSUD DR Moewardi Surakarta. (http//eprints.UMS.ac.id/id/eprint/39569)

9. Harigustian, Yayang. Dkk.(2016). Gambaran Karakteristik Pasien Gagal Jantung Usia 45-65 Tahun di Rumah Sakit PKU Muhammadyah Gamping Sleman. Indonesia Journal of Nursing Practices Voll No1. Uvirsitas Muhammadyah: Jogyakarta.

10. Liana Phey, dkk (2018). Prevalensi Kejadian Penyakit Menular seksual (HIV, Hepatitis B, Hepatitis $C$ dan sefilis) pada wanita penjaja seks di Palembang, Sriwijaya Journal of Medicine, Vol 1 No 2. FK Unsri. PalembangMustofa Usman, dkk, (2008) "Pengantar Teknik Analisis Data" Sinar Baru Algensindo, Bandar Lampung 